\title{
Clinical Features and Prognosis of Henoch-Schönlein Purpura in Children and Adults: A 13-Year Retrospective Study at a Single Centre
}

\author{
Do Young Jung, M.D. ${ }^{1}$ \\ Ye Rim Kwon, M.D. ${ }^{1}$ \\ Min Heui Yu, B.S. ${ }^{2}$ \\ Mee Kyung Namgoong, M.D. ${ }^{1}$ \\ Department of Pediatrics ${ }^{1}$, Yonsei \\ University Wonju College of Medicine, \\ Wonju, Korea, Center of Biomedical \\ Data Science ${ }^{2}$, Yonsei University Wonju \\ College of Medicine, Wonju, Korea
}

Corresponding author:

Mee Kyung Namgoong, M.D.

Department of Pediatrics, Yonsei University

Wonju College of Medicine, 20 Ilsan-ro, Ilsan-ong, Wonju-si, Kangwon-do 26426, Korea

Tel: +82-33-741-1282

Fax: +82-33-732-6229

E-mail:ngmk@yonsei.ac.kr

Received: 21 August 2017

Revised: 21 September 2017

Accepted: 27 September 2017
Purpose: To investigate differences in clinical features, blood/urinary findings, and prognosis in different age groups of patients with Henoch-Schönlein purpura (HSP).

Methods: A total of 469 patients with HSP were analyzed retrospectively from June 2003 to February 2016. We classified patients into child or adult groups based on their age.

Results: The adult group had more patients with anemia (child vs. adult; $7.5 \%$ vs. $16.4 \%)$, and higher immunoglobulin A (IgA) (30.0\% vs. 50.0\%) levels, C-reactive protein $(34.2 \%$ vs. $54.0 \%)$ and uric acid (3.1\% vs. $12.1 \%)$ levels than the child group. The child group was highly positive for Mycoplasma pneumoniae immunoglobulin M (IgM) (34.4\%). More patients in the child group presented with high levels of antistreptolysin 0 ( $24.7 \%$ vs. $2.9 \%$ ) and high C4 (11.5\% vs. $4.2 \%)$. Low C3 (1.1\% vs. 10.2\%) levels, and renal involvement with gross hematuria (8.6\% vs. 21.5 $\%)$, nonnephrotic proteinuria (1.1\% vs. $11.2 \%)$, and nephrotic syndrome $(1.1 \%$ vs. $6.0 \%)$ were common in the adult group. Adults also had poorer renal outcomes [persistent hematuria/proteinuria (10.5\% vs. 32.8\%), and chronic kidney disease ( $0 \%$ vs. $11.2 \%)$ ] than the child group. Risk factors for renal involvement such as older age and higher level of uric acid were only found in the child group. The risk factors for poor renal outcome were nephrotic syndrome in the child group and gross hematuria in the adult group.

Conclusion: In this study, child and adult groups presented with different clinical manifestations of HSP. We found that risk factors for renal involvement included age and high uric acid level in the child group. Moreover, nephrotic syndrome in the child group and gross hematuria in the adult group increased the risk of poor renal outcome.

Key words: Henoch-Schönlein Purpura, Children, Adult, Clinical feature, Prognosis

\section{Introduction} Attribution Non-Commercial License (http:/ creativecommons.org/licenses/by-nc/4.0/) which permits unrestricted non-commercial use, distribution, and reproduction in any medium, provided the original work is properly cited.
In children, Henoch-Schönlein purpura (HSP) is a common form of systemic vasculitis that is known to generally have a favorable prognosis ${ }^{1,2)}$. Conversely, in adults, the prevalence of HSP is low, but is also more likely to show renal involvement, resulting in a poor prognosis ${ }^{3,4)}$. However, although reports have compared the differences between children and adults with respect to HSP, the studies were limited by the lack of cases and short observation pe- 
riods, and there have been few reports on experimentally or clinically specific differences and prognoses ${ }^{5-7)}$. In the present study, we retrospectively reviewed 469 cases of HSP in children and adults, over a period of 13 years, and examined differences in their clinical characteristics, examination outcomes, and prognoses.

\section{Material and methods}

We performed a retrospective study using medical records from a total of 469 inpatients and outpatients who had been diagnosed with HSP at the Department of Pediatrics, Department of Nephrology, Department of Rheumatology, or Department of Dermatology at the Wonju Severance Christian Hospital, between June 2003 and February 2016. The patients were divided into a child group aged 18 years or younger (353 patients) and an adult group aged over 18 years (116 patients). In accordance with the criteria of the European League against Rheumatism/Paediatric Rheumatology International Trials Organization/ Paediatric Rheumatology European Society (EULAR/ PRINTO/PRES), all patients were diagnosed with HSP if they showed palpable purpura and had at least one of the following accompanying conditions: a) abdominal pain; b) arthritis or arthralgia; c) biopsy of affected tissue demonstrating predominant immunoglobulin A (IgA) deposition; and/or d) renal involvement ${ }^{8)}$.

Predisposing factors were classified as upper respiratory tract infection (URI), cancer, or drugs. In terms of clinical manifestations, we investigated skin lesions, joint pain, and gastrointestinal (GI) symptoms. The laboratory studies performed were erythrocyte sedimentation rate (ESR), hemoglobin, white blood cell (WBC) count, C-reactive protein (CRP), blood urea nitrogen (BUN), uric acid, C3/ $\mathrm{C} 4$, PCR for eight strains of respiratory virus (adenovirus, corona virus, influenza A and influenza B, respiratory syncytial virus (RSV), metapneumovirus, rhinovirus, parainfluenza virus), antistreptolysin O (ASO), Mycoplasma Pneumoniae-immunoglobulin M (IgM), and IgA, performed at the time of initial admission to the hospital. Test results were classified as demonstrating an increase or a decrease, based on the reference values in the $20^{\text {th }}$ edition of the Nelson Textbook of Pediatrics and the $19^{\text {th }}$ edition of the Harrisons Principles of Internal Medicine ${ }^{9,10)}$.

Renal involvement was categorized in terms of microscopic/gross hematuria, proteinuria, nephrotic syndrome, and normal, based on urinalysis performed throughout the period of care. Renal outcome was classified as normal urine, persistent hematuria \pm proteinuria, or chronic kidney disease (CKD; denoted by continually elevated $\mathrm{Cr}$, or by the patient being a recipient of dialysis or kidney transplant). Persistent urinary abnormalities or CKD were defined as poor renal outcome, and a binary logistic regression analysis was performed.

SPSS 18.0 (IBM Corp., Armonk, NY, USA) was used for statistical analysis, and chi-square test or Fisher's exact test was used to compare categorical variables. A binary logistic regression analysis was performed. $P<0.05$ was defined as a statistically significant result.

\section{Results}

\section{Patients characteristics}

There were a total of 469 patients included in this study. The mean age was $7.62 \pm 3.76$ years in the child group (353 patients; $1-18$ years) and $47.8 \pm 18.0$ years in the adult group (116 patients; $19-87$ years). In terms of sex ratio, male patients were more common in both groups (child vs. adult; $53.8 \%$ vs. $52.6 \%, P=0.905)$. The mean follow-up duration was 392.5 days for the child group and 565.1 days for the adult group.

In terms of predisposing factors, URI was the most common in the child group ( $45.9 \%$ vs. $23.3 \%, P<0.001)$.

Drug use was reported in 17 adults solely (colchicine, dapsone, triamcinolone, antidiabetic/antihypertensive drugs, 13.8\%), and cancer was reported in three adults only (Hodgkin's lymphoma, adenocarcinoma, ovarian cancer, 2.6\%). Spring was the highest frequency for both group (30.3\% vs. $27.6 \%, P=0.66$ ), antithetically summer was the lowest frequency for both group ( $14.7 \%$ vs. $19.0 \%, P=0.347$ ).

In terms of skin lesions, purpura was observed on the lower limb in $85.5 \%$ of child patients and $59.5 \%$ of adult patients, and could be seen frequently in other locations in adults $(P<0.001)$. Joint pain was significantly more frequent in the child group than in the adult group ( $54.4 \%$ vs. $27.6 \%$, $P<0.001)$. Overall GI symptoms were more frequent in the 
adult group (36.8\% vs. $37.1 \%, P=0.510)$ than in the child group, but there was no significant difference between two groups. In terms of specific symptoms, abdominal pain was more frequent in the child group (31.2\% vs. $26.6 \%, P=$ $0.411)$ than in the adult group, while nausea/vomiting $(2.0$ $\%$ vs. $2.6 \%, P=0.711$ ), and hematochezia ( $1.4 \%$ vs. $7.1 \%, P=$ 0.007 ) were more frequent in the adult group, differences of hematochezia were statistically significant (Table 1).

\section{Laboratory outcomes}

The mean test results for platelet count $(372,030 \pm 120,726$ $\times 10^{6} / \mathrm{L}$ vs. $\left.278,786 \pm 108,779 \times 10^{6} / \mathrm{L}, P<0.001\right)$ were significantly higher in the child group. Compared with the child group, the adult group showed a greater increase in anemia (7.5\% vs. $16.4 \%, P=0.006)$, C3 hypocomplementemia (1.1\% vs. $10.2 \%, P=0.002)$, C3 hypercomplementamia ( $3.6 \%$ vs. $4.1 \%, P=1.0)$, and $\mathrm{C} 4$ hypocomplementemia ( $1.8 \%$ vs. $2.1 \%$, $P=0.302$ ). While the child group were common in $\mathrm{C} 4 \mathrm{hy}$ percomplementemia ( $11.5 \%$ vs. $4.2 \%, P=0.033)$ than the adult group. Uric acid showed a higher mean value in adult patients than in child patients $(4.09 \pm 1.2 \mathrm{mg} / \mathrm{dL} v s .5 .50 \pm 1.5$ $\mathrm{mg} / \mathrm{dL}, P<0.001)$; the number of patients showing hyperuricemia was also higher in the adult group than in the child group (3.1\% vs. $12.1 \%, P=0.042$ ) (Table 2).

Mycoplasma antibody was detected in $34.4 \%$ of cases in the child group. The positive rate of polymerase chain reaction (PCR) for respiratory viruses were $8.8 \%$, adenovirus, RSV type A, and rhinovirus were detected in child.

High ASO (24.7\% vs. $2.9 \%, P<0.001)$ was more common in the child group. The level of high IgA (30.0\% vs. $50.0 \%$, $P<0.001)$ was greater in the adult group than that in the child group.

\section{Renal involvement and poor renal outcomes}

Renal involvement was significantly more common in adult patients than in child patients (gross hematuria 8.6\% vs. $21.5 \%, P<0.001$; nonnephrotic proteinuria, $1.1 \%$ vs. 11.2 $\%, P<0.001$; nephrotic syndrome, $1.1 \%$ vs. $6.0 \%, P=0.007$ ). Microspcopic hematuria was no significantly difference between two groups (21.4\% vs. 26.7\%, $P=0.293$ ) (Table 2).

With this, poor renal outcomes were more common in the adult group $(10.5 \%$ vs. $44 \%, P<0.001)$ than in the child

Table 1. Clinical Characteristic between Child and Adult Group

\begin{tabular}{|c|c|c|c|c|}
\hline \multirow{2}{*}{ Variable } & Total $n=469$ & Child group $n=353(75.3 \%)$ & Adult group $n=116(24.7 \%)$ & $P$ value \\
\hline & \multicolumn{4}{|c|}{ No. of patients (\%) } \\
\hline Male(\%) & $251(53.5)$ & $190(53.8)$ & $61(52.6)$ & 0.902 \\
\hline Season & & & & 0.696 \\
\hline Spring & $139(29.6)$ & $107(30.3)$ & $32(27.6)$ & 0.66 \\
\hline Summer & 74 (15.8) & $52(14.7)$ & $22(19.0)$ & 0.347 \\
\hline Fall & $130(27.7)$ & $97(27.5)$ & $33(28.4)$ & 0.934 \\
\hline Winter & $126(26.9)$ & $97(27.5)$ & $29(25.0)$ & 0.688 \\
\hline Predisposing factor & & & & $<0.001$ \\
\hline URI & $189(40.3)$ & $162(45.9)$ & $27(23.3)$ & $<0.001$ \\
\hline Drug & $16(3.4)$ & $0(0)$ & $16(13.8)$ & $<0.001$ \\
\hline Cancer & $3(0.6)$ & $0(0)$ & $3(2.6)$ & 0.009 \\
\hline Purpura sites & & & & $<0.001$ \\
\hline Lower extremities & $371(79.1)$ & $302(85.5)$ & $69(59.5)$ & $<0.001$ \\
\hline Trunk & $17(3.6)$ & $2(0.6)$ & $15(12.9)$ & $<0.001$ \\
\hline Lower and Upper extremities & $37(7.9)$ & $29(8.2)$ & $8(6.9)$ & 0.796 \\
\hline Whole body & $44(9.4)$ & $20(5.7)$ & $24(20.7)$ & $<0.001$ \\
\hline Joint pain & $224(47.8)$ & $192(54.4)$ & $32(27.6)$ & $<0.001$ \\
\hline Gastrointestinal symptoms & $173(36.9)$ & $130(36.8)$ & $43(37.1)$ & 0.510 \\
\hline Abdominal pain & $140(30.0)$ & $110(31.2)$ & $30(26.6)$ & 0.411 \\
\hline Nausea/vomiting & $10(2.2)$ & $7(2.0)$ & $3(2.6)$ & 0.711 \\
\hline Diarrhea & $10(2.2)$ & $8(2.3)$ & $2(1.8)$ & 1.0 \\
\hline Hematochezia & $13(2.8)$ & $5(1.4)$ & $8(7.1)$ & 0.007 \\
\hline
\end{tabular}


group, and cases that progressed to CKD were only observed in adults (11.2\%). The majority of child patients had a normal outcome (whereas approximately half the adult patients had a normal outcome ( $89.5 \%$ vs. $56.0 \%, P<0.001)$.

\section{Univariate and multivariate logistic regression} and odd ratio for renal involvement and outcomes

A univariate logistic regression analysis was used to analyze several factors that might influence renal involvement. Of these, the factors with a statistically significant effect on renal involvement were age (OR 1.09, $P=0.004$ in the univariate analysis $\mathrm{OR} 1.10, P=0.045$ in the multivariate analysis), high uric acid (OR 10.50, $P=0.034$ in the univariate analysis OR 5.03, $P=0.041$ in the multivariate analysis in child group). There was no significant risk factor on renal involvement in adult group (Table 3).

Another univariate logistic regression analysis was used to analyze the factors that might influence renal outcomes. The factors significantly associated with renal outcomes in this analysis were then subjected to an additional multiva- riate logistic regression analysis. The child group were presented nephrotic syndrome (OR 258.9, $P=0.013$ in the univariate analysis and OR 249.71, $P=0.016$ in the multivariate analysis). And adult group show gross hematuria (OR 49.3, $P=0.014$ in the univariate analysis and $100.63, P=0.006$ in the multivariate analysis) (Table 4).

\section{Discussion}

Since this study included a total of 469 HSP patients, it can be considered a large-scale study as compared with previous research. With respect to the clinical observations made involving adults and children from several prior studies on fewer patients, the present study generally shows a greater difference in prognoses ${ }^{11,12)}$.

Among predisposing factors in the present study, the incidence of URI was significantly high in the child group. This is similar to trends seen in previous studies. The etiology of URI was only tested in some child patients in this

Table 2. Laboratory Results between Child and Adult Group

\begin{tabular}{|c|c|c|c|c|}
\hline & Total $n=469$ & Child group $n=353$ (75.3\%) & Adult group $n=116(24.7 \%)$ & $P$ value \\
\hline & \multicolumn{4}{|c|}{ No. of patients (\%) } \\
\hline WBC $\left(\times 10^{6} / \mathrm{L}\right)$ & $9,744.5 \pm 3,695.9$ & $9,919 \pm 3,580.7$ & $9,224.7 \pm 3,990.3$ & 0.08 \\
\hline Platelet (x10 6 /L) & $348,567 \pm 124,492$ & $372,030 \pm 120,726$ & $278,786 \pm 108,779$ & $<0.001$ \\
\hline $\operatorname{lgA}(\mathrm{mg} / \mathrm{dL})$ & $205.9 \pm 96.7$ & $191.5 \pm 82.7$ & $321.4 \pm 121.8$ & $<0.001$ \\
\hline Uric acid (mg/dL) & $4.3 \pm 1.3$ & $4.1 \pm 1.2$ & $5.5 \pm 1.5$ & $<0.001$ \\
\hline Anemia $(n=461)$ & $45(9.8)$ & $26(7.5)$ & 19 (16.4) & 0.009 \\
\hline High CRP ( $n=291)$ & $112(38.5)$ & $78(34.2)$ & $34(54.0)$ & $<0.001$ \\
\hline High uric acid $(n=226)$ & $10(4.4)$ & $6(3.1)$ & $4(12.1)$ & 0.042 \\
\hline High $\lg A(n=270)$ & $87(32.2)$ & $72(30.0)$ & $15(50.0)$ & $<0.001$ \\
\hline Low C3 ( $n=327)$ & $8(2.5)$ & $3(1.1)$ & $5(10.2)$ & 0.002 \\
\hline High C4 ( $n=327)$ & $34(10.4)$ & $32(11.5)$ & $2(4.2)$ & 0.033 \\
\hline M. pneumoniae $\lg M(+)(n=296)$ & $102(34.4 \%)$ & $102(34.4)$ & No data & \\
\hline High ASO $(n=321)$ & $72(22.4)$ & $71(24.7)$ & $1(2.9)$ & $<0.001$ \\
\hline Renal involvement & & & & $<0.001$ \\
\hline Microscopic hematuria & $106(22.7)$ & $75(21.4)$ & $31(26.7)$ & 0.293 \\
\hline Gross hematuria & $55(11.8)$ & $30(8.6)$ & $25(21.5)$ & $<0.001$ \\
\hline Nonnephrotic proteinuria & $17(3.6)$ & $4(1.1)$ & $13(11.2)$ & $<0.001$ \\
\hline NephroticSyndrome & $11(2.4)$ & $4(1.1)$ & $7(6.0)$ & 0.007 \\
\hline Renal outcome & & & & $<0.001$ \\
\hline Normal urine & $380(81.2)$ & $315(89.5)$ & $65(56.0)$ & $<0.001$ \\
\hline Persistent hematuria/proteinuria & $75(16.0)$ & $37(10.5)$ & $38(32.8)$ & $<0.001$ \\
\hline Chronic kidney disease & $13(2.8)$ & $0(0)$ & $13(11.2)$ & $<0.001$ \\
\hline
\end{tabular}

*Plus-minus values are means \pm SD.

Abbreviations: WBC, white blood cell; ESR, erythrocyte sedimentation rate; CRP, C-reactive protein; ASO, antistreptolysin 0. 
Table 3. Results of Univariate and Multivariate Logistic Regression Analysis of the Risk of Renal Involvement in HSP Patients

\begin{tabular}{|c|c|c|c|c|c|c|c|c|}
\hline \multirow{3}{*}{ Variable } & \multicolumn{4}{|c|}{ Child group } & \multicolumn{4}{|c|}{ Adult group } \\
\hline & \multicolumn{2}{|c|}{ Univariate } & \multicolumn{2}{|c|}{ Multivariate } & \multicolumn{2}{|c|}{ Univariate } & \multicolumn{2}{|c|}{ Multivariate } \\
\hline & OR (95\%Cl) & $P$ value & OR (95\%Cl) & $P$ value & OR $(95 \% \mathrm{Cl})$ & $P$ value & OR $(95 \% \mathrm{Cl})$ & $P$ value \\
\hline Age & $1.09(1.03-1.16)$ & 0.004 & $1.10(1.0-1.21)$ & 0.045 & $0.99(0.97-1.02)$ & 0.552 & $0.81(0.65-1.02)$ & 0.420 \\
\hline $\operatorname{Sex}(M)$ & $1.00(0.64-1.57)$ & 0.996 & $12.56(1.0-158.85)$ & 0.051 & $0.86(0.4-1.86)$ & 0.706 & $0.59(0.24-1.43)$ & 0.24 \\
\hline \multicolumn{9}{|l|}{ Purpura sites } \\
\hline Whole body & $1.40(0.55-3.53)$ & 0.97 & $0.92(0.35-2.44)$ & 0.868 & $0.32(0.12-0.84)$ & 0.141 & $0.30(0.11-0.81)$ & 0.081 \\
\hline Joint pain & $0.74(0.47-1.16)$ & 0.194 & & & $1.50(0.61-3.64)$ & 0.376 & & \\
\hline \multicolumn{9}{|l|}{ Gl symptoms } \\
\hline Abdominal pain & $1.63(1.01-2.65)$ & 0.528 & & & $2.32(0.88-6.13)$ & 0.932 & & \\
\hline Hematochezia & $1.67(0.27-10.2)$ & 0.763 & & & $0.71(0.16-3.06)$ & 0.915 & & \\
\hline M. pneumonia IgM & $1.43(0.88-2.33)$ & 0.154 & & & & & & \\
\hline High ASO & $1.18(0.67-2.07)$ & 0.577 & & & & & & \\
\hline High $\lg A$ & $1.19(0.67-2.11)$ & 0.555 & & & $1.0(0.06-17.62)$ & 1.0 & & \\
\hline High uric acid & $10.50(1.2-91.86)$ & 0.034 & $5.03(0.95-26.49)$ & 0.041 & $0.48(0.04-5.83)$ & 0.565 & $0.357(0.01-97.21)$ & 0.719 \\
\hline Low C3 & $3.62(0.32-40.42)$ & 0.118 & $1.04(0.99-1.10)$ & 0.149 & $0.41(0.06-2.83)$ & 0.964 & & \\
\hline High C4 & $0.32(0.12-0.85)$ & 0.016 & $0.90(0.80-1.02)$ & 0.205 & - & - & & \\
\hline Anemia & $2.85(1.27-6.40)$ & 0.011 & $2.80(0.02-524.57)$ & 0.702 & $1.58(0.53-4.76)$ & 0.416 & & \\
\hline Low hematocrit & $2.89(1.52-5.5)$ & 0.001 & $4.49(0.05-473.32)$ & 0.497 & $1.52(0.45-5.13)$ & 0.497 & & \\
\hline High ESR & $1.23(0.63-2.43)$ & 0.545 & & & $0.96(0.27-3.41)$ & 0.954 & & \\
\hline High CRP & $0.93(0.51-1.69)$ & 0.805 & & & $1.26(0.44-3.66)$ & & & \\
\hline
\end{tabular}

Abbreviations: OR, odd ratio; Cl, confidence interval; WBC, white blood cell; ESR, erythrocyte sedimentation rate; CRP, C-reactive protein; ASO, antistreptolysin O.

Table 4. Results of Univariate and Multivariate Logistic Regression Analysis of the Risk of Poor Renal Outcome in HSP Patients

\begin{tabular}{|c|c|c|c|c|c|c|c|c|}
\hline \multirow{3}{*}{ Variable } & \multicolumn{4}{|c|}{ Child group } & \multicolumn{4}{|c|}{ Adult group } \\
\hline & \multicolumn{2}{|l|}{ Univariate } & \multicolumn{2}{|l|}{ Multivariate } & \multicolumn{2}{|l|}{ Univariate } & \multicolumn{2}{|l|}{ Multivariate } \\
\hline & OR $(95 \% \mathrm{Cl})$ & $P$ value & OR $(95 \% \mathrm{Cl})$ & $P$ value & OR $(95 \% \mathrm{Cl})$ & $P$ value & OR $(95 \% \mathrm{Cl})$ & $P$ value \\
\hline Age & $1.08(0.99-1.17)$ & 0.085 & & & $1.02(1.00-1.04)$ & 0.1 & & \\
\hline $\operatorname{Sex}(M)$ & $1.30(0.65-2.60)$ & 0.458 & $1.16(0.50-2.68)$ & 0.735 & $1.57(0.75-3.29)$ & 0.234 & $2.34(0.79-6.91)$ & 0.124 \\
\hline \multicolumn{9}{|l|}{ Purpura sites } \\
\hline Whole body & $1.54(0.43-5.54)$ & 0.554 & $0.84(0.38-1.88)$ & 0.685 & $0.36(0.13-1.03)$ & 0.047 & $0.36(0.13-1.03)$ & 0.047 \\
\hline Joint pain & $0.68(0.34-1.35)$ & 0.269 & & & $1.18(0.52-2.67)$ & 0.697 & & \\
\hline \multicolumn{9}{|l|}{ Gl symptoms } \\
\hline Abdominal pain & $2.07(1.02-4.20)$ & 0.937 & & & $0.67(0.27-1.64)$ & 0.925 & & \\
\hline M. pneumonia lgM & $1.22(0.59-2.55)$ & 0.593 & & & & & & \\
\hline High ASO & $1.02(0.44-2.38)$ & 0.971 & & & & & & \\
\hline High lgA & $0.75(0.31-1.86)$ & 0.54 & & & $2.41(0.52-11.10)$ & 0.260 & & \\
\hline High uric acid & $1.76(0.20-15.85)$ & 0.615 & & & $2.44(0.23-26.30)$ & 0.463 & & \\
\hline Low C3 & $3.78(0.33-42.85)$ & 0.289 & & & $0.23(0.02-2.21)$ & 0.971 & & \\
\hline High C4 & $0.22(0.03-1.67)$ & 0.126 & & & - & - & & \\
\hline Anemia & $1.63(0.53-5.03)$ & 0.54 & & & $0.91(0.34-2.47)$ & 0.859 & & \\
\hline \multicolumn{9}{|l|}{ Renal involvement } \\
\hline Microscopic hematuria & $30.9(8.89-107.4)$ & 0.774 & $28.89(8.27-100.97)$ & 0.65 & $10.16(2.57-40.8)$ & 0.35 & 17.07 (2.91-100.15) & 0.719 \\
\hline Gross hematuria & $28.3(7.0-114.68)$ & 0.953 & $22.55(5.38-94.53)$ & 0.91 & $49.3(10.6-228.1)$ & 0.014 & $100.63(14.03-721.77)$ & 0.006 \\
\hline Nonnephrotic proteinuria & $78.0(8.0-752.56)$ & 0.22 & $47.45(3.50-643.86)$ & 0.489 & $19.73(3.90-99.9)$ & 0.597 & $26.44(3.47-201.23)$ & 0.674 \\
\hline Nephrotic syndrome & $285.9(18.57-2,947.95)$ & 0.013 & $249.71(19.63-1,336.4)$ & 0.016 & $73.9(6.57-833.7)$ & 0.071 & $78.63(3.71-851.53)$ & 0.209 \\
\hline
\end{tabular}

Abbreviations: OR, odd ratio; Cl, confidence interval; WBC, white blood cell; ESR, erythrocyte sedimentation rate; CRP, C-reactive protein; ASO, antistreptolysin o. 
study; adenovirus, RSV type A, and rhinovirus were detected in one case each, and the overall virus positive ratio was $8.8 \%$. There was a suspicion that these infections were preceded, but there was no relation with the rate of kidney involvement. According to previous studies, the main causes of URI are viruses (parvovirus, rhinovirus) ${ }^{13)}$ and bacteria (staphylococci, streptococci) ${ }^{14)}$.

Medication with drugs prior to HSP onset was only common in adult patients, and that didn't show an effect on renal prognosis in our study. The drugs taken included colchicine, dapsone, triamcinolone, and antidiabetic/antihypertensive drugs. In previous studies, quinolones ${ }^{15}$ and clarithromycin ${ }^{16)}$ were reported to be associated with HSP. Cancer was observed in only three cases involving adult patients; the types of cancer were Hodgkin's lymphoma, adenocarcinoma, and ovarian cancer, and these had an effect on renal prognosis. Other studies have reported lung (nonsmall-cell) cancer ${ }^{17)}$, multiple myeloma ${ }^{18)}$, prostate cancer $^{19)}$, Hodgkin's lymphoma ${ }^{20)}$ and non-Hodgkin's lymphoma ${ }^{21)}$.

In terms of purpura distribution, a study by Kang ${ }^{11)}$ reported significantly higher involvement of the upper and lower limbs in the adult group; the present study also found that purpura was not limited to the lower limbs in $40.5 \%$ of cases for adults (vs. 14.4\% for children). Joint pain was known to be more frequent in children in previous studies, and was also frequently observed in child patients in the present study. GI symptoms did not show any major differences between in the child $v s$. the adult patients in previous studies. Our study also found no differences in overall GI symptoms. But in terms of specific symptoms, we observed only abdominal pain was common in child patients, whereas abdominal pain with hematochezia more frequently in adult patients.

Renal involvement itself is a controversial issue, but generally previous studies have shown a pattern of more involvement in adults. Carlos ${ }^{5)}$ and Hung et al. ${ }^{11)}$ reported that only microscopic hematuria and renal insufficiency were more common in adults. In contrast, the present study found that microscopic hematuria had not difference of frequency, whereas gross hematuria, nonnephrotic proteinuria, and nephrotic syndrome were more common in adults. Previous studies documented the risk factors of renal involvement in child were increased level of plasma creatinine and hypertension $^{22)}$. Whereas we found that risk factors for renal involvement include older age and high level of serum uric acid in the child group. The adult group didn't show any risk factors for renal involvement in this study.

Renal outcomes showed significantly better prognoses for children $(89.5 \%$ vs. $56 \%, P<0.001)$ than for adults. Previous studies have reported proteinuria, hypertension, and anemia as major negative factors ${ }^{5,11,23)}$. Other studies asserted that the risk factors of renal outcomes were presence of nephrotic syndrome, severe case of histologic findings of kidney in child group ${ }^{24,25)}$. Butani and Morgenstern claimed that no apparent risk factor of poor renal outcomes in child$\mathrm{ren}^{26)}$. Other risk factors reported to be associated with worse prognosis in adults are severe renal symptoms at onset, female sex (during and after pregnancy), and increased serum creatinine level and proteinuria on renal biopsy ${ }^{27-29)}$. We found that factors affecting persistent or proceeding renal dysfunction were nephrotic syndrome in child group and gross hematuria in adult group.

A previous study demonstrated that hyperuricemia in IgA nephropathy patients was a predictive factor for progressive nephropathy and that allopurinol could improve hypertension ${ }^{30}$. Our study show hyperuricamia was risk factor of renal involvement in child group, but that was not relation to poor renal outcomes. We postulate that the reason for the difference between the results obtained in this study and those reported in previous studies is that we performed uric acid studies in fewer patients in the adult group and the prognosis of renal outcomes in the child group was generally better than that in the adult group.

There have been reports that blood IgA level is elevated in more than half of HSP patients, and that renal involvement is associated with higher $\operatorname{IgA}{ }^{31-33)}$. In our study, rates of increased IgA level were $32.2 \%$ on all patients and we also found a clear increase in mean IgA levels in the adult group. The rate of kidney involvement was also more common in adults, that was consistent with previous studies. But high IgA level was not risk factor of renal involvement in the multivariate analysis.

Studies on complements in children have reported that some patients show a temporary decrease in $\mathrm{C} 3$, but that complement levels are not a prognostic factor for renal involvement ${ }^{34,35)}$. Kawasa et al. ${ }^{36)}$ reported that terminal 
complement complex showed increased levels in the blood in $83 \%$ of patients in the acute phase, and that it was associated with relapse during follow-up, but that C3 and C4 showed normal or elevated levels. However, there have also been reports that it is impossible to prove that complement activation is involved in the pathogenic mechanism of HSP ${ }^{37)}$. We found that increased $\mathrm{C} 4$ was more common than decreased C4 regardless of age. However, it was neither a risk factor for renal involvement, nor a prognostic factor for renal outcomes.

$M$. pneumoniae infection shows non-lung symptoms in $25 \%$ of cases, and sometimes causes a rash. M. pneumoniae IgM-positive HSP patients have been reported previously ${ }^{38)}$. In the present study, $34.4 \%$ of child patients were positive for M. pneumoniae, that was more frequent than positive ratio of high ASO titer (22.4\%). Nonetheless, given that other research organizations have also shown an interest in this area, we believe that further discussion is required about the potential significance of macrolide antibiotics in HSP treatment.

This study had some limitations. First, as a retrospective study, there were cases lost to follow-up. Second, the treatment of HSP was mostly conducted at the Department of Pediatrics for child patients, and at various departments for adult patients. Hence, the level of consistency in examinations and medication administration is not clear, and so the comparison between child patients and adult patients is not perfect. Third, the small number of adult cases as compared with the number of child cases could have caused statistical bias.

In conclusion, in our study, HSP showed different clinical patterns in children and in adults. Risk factors for renal involvement were age and high level of uric acid in child group. Risk factors for renal outcomes were nephrotic syndrome in the children group, and gross hematuria in the adult group. In addition, further long-term follow-up observations and large-scale studies are required in the future to investigate the relationship between $M$. pneumoniae and HSP.

\section{Conflicts of interest}

No potential conflict of interest relevant to this article was reported.

\section{Reference}

1. Narchi H. Risk of long term renal impairment and duration of follow up recommended for Henoch-Schönlein purpura with normal or minimal urinary findings: a systematic review. Arch Dis Child 2005;90:916-20.

2. Goldstein AR, White RH, Akuse R, Chantler C.Long-term followup of childhood Henoch-Schönlein nephritis. The Lancet 1992; 339:280-2.

3. Pillebout E, Thervet E, Hill G, Alberti C, Vanhille P, Nochy D. HenochSchönleinpurpura in adults: outcome and prognostic factors. J Am SocNephrol 2002;13:1271-8.

4. Ronkainen J, Nuutinen M, Koskimies O.The adult kidney 24 years after childhood Henoch-Schönlein purpura: a retrospective cohort study. The Lancet 2002;360:666-70.

5. García-Porrúa C, Calviño MC, Llorca J, Couselo JM, González-Gay MA. Henoch-Schönlein purpura in children and adults: clinical differences in a defined population. Semin Arthritis Rheum 2002; 32:149-56.

6. Trapani S, Micheli A, Grisolia F, Resti M, Chiappini E, Falcini F, et al. Henoch Schonlein purpura in childhood: epidemiological and clinical analysis of 150 cases over a 5-year period and review of literature. Semin Arthritis Rheum 2005;35:143-53.

7. Komatsu, H, Fujimoto, S, Yoshikawa, N, Kitamura, H, Sugiyama, H, Yokoyama H. Clinical manifestations of Henoch-Schönlein purpura nephritis and lgA nephropathy: comparative analysis of data from the Japan Renal Biopsy Registry (J-RBR). Clin Exp Nephrol 2016;20:552-60.

8. Ozen S, Pistorio A, lusan SM, Bakkaloglu A, Herlin T, Brik R, et al. EULAR/PRINTO/PRES criteria For Henoch-Schönlein purpura, childhood polyarteritis nodosa, childhood Wegener granulomatosis and childhood Takayasu arteritis: Ankara 2008. Part II: final classification criteria. Ann Rheum Dis 2010;69:798-806.

9. Stanley F. Lo. Reference intervals for laboratory tests and procedures. In:Behrman RE, Kliegman RM, Stanton BF, Geme JW, Schor NF, editors. Nelson Textbook of Pediatrics. 20th ed. Philadephia: Elsevier, 2015: 3464-73.

10. Kratz A, Pesce MA, Basner RC, Einstein AJ. Laboratory Values of Clinical Importance. In: Kasper D, Fauci A, Hauser S, Longo D, Jameson J, Loscalzo J. editors. Harrison's Principles of Internal Medicine, 19ed. New York:McGraw-Hill, 2014:2754-64.

11. Hung SP, Yang YH, Lin YT, Wang LC, Lee JH, Chiang BL. Clinical manifestations and outcomes of Henoch-Schönlein purpura: comparison between adults and children. Pediatr Neonatol 2009:50:162-8.

12. Kang Y, Park JS, Ha YJ, Kang MI, Park HJ, Lee SW, et al. Differences in clinical manifestations and outcomes between adult and child patients with Henoch-Schönlein purpura. J Korean Med Sci 2014; 29:198-203. 
13. Veraldi S, Mancuso R, Rizzitelli G, Gianotti R, Ferrante P. HenochSchonlein syndrome associated with human Parvovirus B19 primary infection. Eur J Dermatol 1999;9:232-3.

14. Saulsbury FT. Henoch-Schonlein Purpura in Children: Report of 100 Patients and Review of the Literature. Medicine 999;78:395409.

15. Drago F, Arditi MR, Rebora A. Henoch-Schönlein purpura induced by fluoroquinolones. Br J Dermatol 1994;131:448.

16. Borrás-Blasco J, Enriquez R, Amoros F, Cabezuelo JB, Navarro-Ruiz A, Pérez M, et al. Henoch-Schönlein purpura associated with clarithromycin. Case report and review of literature. IntJ Clin Pharmacol Ther 2003;41:213-6.

17. Blanco R, González-Gay MA, Ibáñez D, Alba C, Pérez de Llano LA. Henoch-Schönlein purpura as a clinical presentation of small cell lung cancer. ClinExpRheumatol1997;15:545-7.

18. Zickerman AM, Allen AC, Talwar V, Olczak SA, Brownlee A, Holland $M$, et al. IgA myeloma presenting as Henoch-Schönlein purpura with nephritis. Am J Kidney Dis 2000;36:E19.1-5.

19. Garcias VA, Herr HW. Henoch-Schonlein purpura associated with cancer of prostate. Urology 1982;19:155-8.

20. Blanco P, Denisi R, Rispal P, Deminière C, Pellegrin JL, Leng B, et al. Henoch-Schönlein purpura associated with segmental and focal proliferative glomerulonephritis in a patient with Hodgkin's disease. Nephrol Dial Transplant 1999;14:179-80.

21. Day C, Savage CO, Jones EL, Cockwell P. Henoch-Schönlein nephritis and non-Hodgkin's lymphoma. Nephrol Dial Transplant 2001;16:1080-1.

22. Hung SP, Yang YH, Lin YT, Wang LC, Lee JH, Chiang BL. Clinical manifestations and outcomes of Henoch-Schönlein purpura: comparison between adults and children. PediatrNeonatol 2009;50:162-8

23. Goldstein, Amanda R., et al. Long-term follow-up of childhood Henoch-Schönlein nephritis. Lancet 1992;1;339:280-2.

24. Schärer K, Krmar R, Querfeld U, Ruder H, Waldherr R, Schaefer F. Clinical outcome of Schönlein-Henoch purpura nephritis in children. Pediatr Nephrol 1999;13:816-23.

25. Calviño MC, Llorca J, García-Porrúa C, Fernández-Iglesias JL, and Rodriguez-Ledo P, et al. Henoch-Schönlein purpura in children from northwestern Spain: a 20-year epidemiologic and clinical study. Medicine 2001;80:279-90.
26. Butani L, Morgenstern BZ. Long-term outcome in children after Henoch-Schonlein purpura nephritis. Clin Pediatr 2007;46:50511.

27. Ronkainen J, Nuutinen M, Koskimies O. The adult kidney 24 years after childhood Henoch-Schönlein purpura: a retrospective cohort study. Lancet 2002;360:666-70.

28. Pillebout E, Thervet E, Hill G, Alberti C, Vanhille P, Nochy D. HenochSchönlein Purpura in adults: outcome and prognostic factors. J Am Soc Nephrol 2002;13:1271-8.

29. Rosanna Coppo, Simeone Andrulli, Alessandro Amore, Bruno Gianoglio, Giovanni Conti, Licia Peruzzi, et al. Predictors of Outcome in Henoch-Schönlein Nephritis in Children and Adults. Am J Kidney Dis 2006;47:993-1003.

30. Shi Y, Chen W, Jalal D, Li Z, Chen W, Mao H, Yang Q, Johnson RJ, et al. Clinical outcome of hyperuricemia in IgA nephropathy: a retrospective cohort study and randomized controlled trial. Kidney Blood Press Res 2012;35:153-60.

31. Calviño MC, Llorca J, García-Porrúa C, Fernández-Iglesias JL, Rodriguez-Ledo P, González-Gay MA. Henoch-Schönlein purpura in children from northwestern Spain: a 20-year epidemiologic and clinical study. Medicine 2001;80:279-90.

32. Trygstad CW, Stiehm ER. Elevated serum IgA globulin in anaphylactoid purpura. Pediatrics 1971;47:1023-8.

33. Davin JC, Ten Berge IJ, Weening JJ. What is the difference between IgA nephropathy and Henoch-Schönlein purpura nephritis? Kidney Int 2001;59:823-34.

34. Motoyama O, litaka K. Henoch-Schonleinpurpura with hypocomplementemia in children. Pediatrlnt 2005;47:39-42.

35. Lin Q, Min Y, Li Y, Zhu Y, Song X, et al. Henoch-Schönlein purpura with hypocomplementemia. PediatrNephrol 2012;27:801-6.

36. Kawana S, Nishiyama S.Serum SC5b-9 (terminal complement complex) level, a sensitive indicator of disease activityin patients with Henoch-Schönlein purpura. Dermatology 1992;184:171-6.

37. Smith GC, Davidson JE, Hughes DA, Holme E, Beattie TJ. Complement activation in Henoch-Schönlein purpura. Pediatr Nephrol 1997;11:477-80.

38. Kuźma-Mroczkowska E, Pańczyk-Tomaszewska M, Szmigielska A, Szymanik-Grzelak H, Roszkowska-Blaim M. Mycoplasma pneumoniae as a trigger for Henoch-Schönlein purpura in children. Cent Eur J Immunol 2015;40:489-92. 